\title{
Conditioning regimens for autologous hematopoietic stem cell transplantation in Lymphoma: Comparison BEAM / BEAC-BUCY-GEMBUMEL
}

Colombo E. Jarchum, S. Alvarez, M. Mas, E. M. Balseiro, M. Lavarda, M. Rizzi, M. Jarchum, G Oncology and Hematology Service. Sanatorio Allende, Córdoba. Argentinarr evycolombo4@gmail.com

\section{Background}

\section{Materials \& Methods}

Hematopoietic stem cell transplantation (HSCT) represents a potentially Retrospective, observational and descriptive study.

curative therapy for certain hematological diseases. Conditioning Pate with $\begin{array}{ll}\text { regimes (CR) are still an area of research. } & \text { non-Hodgkin's Lymphoma (NHL) undergoing autologous HSCT in the }\end{array}$ We present here a comparative study of the CR: BUCY, BEAM-BEAC $2010-2017$ period were included.

and GEMBUMEL in patients $(P)$ with diagnosis of Lymphoma subjected to autologous HSCT.

\section{Objective}

Evaluate the safety and efficacy of these regimens in our experience.

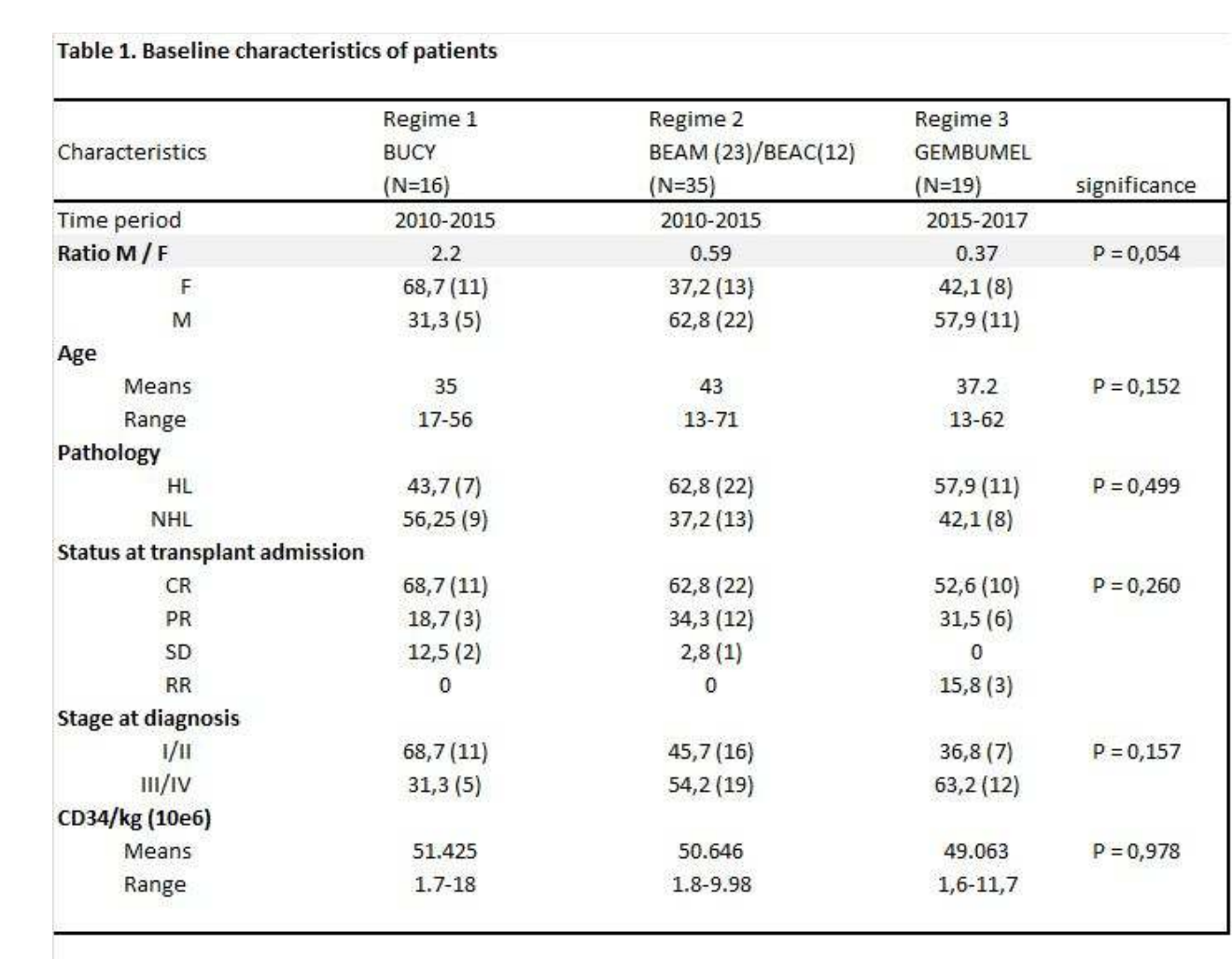
A statistically significant difference was observed in the relationship
between men and women. Grade III-IV of Toxicity were more haematological recovery and transfusional requirement

For the Efficacy analysis, Progression Free Survival (PFS) and S) were evaluated.

Descriptive statistics were used for the numerical variables, ANOVA for the categorical ones, Chi-Square test for comparison of

.

rable 2. Toxicity

\begin{tabular}{|c|c|c|c|c|}
\hline & $\begin{array}{l}\text { Regime } 1 \\
\text { Bunr } \\
(N=16) \\
(N)\end{array}$ & 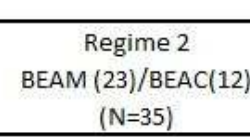 & 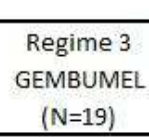 & \\
\hline $\begin{array}{l}\text { Hematological toxicity } \\
\text { Febrile Nuertropenia }\end{array}$ & & & & \\
\hline Mucositis Gull/V & $50(8)$ & $\begin{array}{l}97,133) \\
54,2(19)\end{array}$ & $\begin{array}{l}1000(19) \\
100(19)\end{array}$ & $\begin{array}{l}\begin{array}{l}p=0,613 \\
p=0,001\end{array} \\
=\end{array}$ \\
\hline other GIII/IV & & & & \\
\hline $\begin{array}{l}\text { Occlusive vein disease } \\
\text { Seizure }\end{array}$ & $\begin{array}{l}6,2(1) \\
6,2(1)\end{array}$ & 0 & $\begin{array}{l}5,2(1) \\
0\end{array}$ & $\begin{array}{l}\begin{array}{l}P=0,3,32 \\
p=0,186\end{array} \\
P\end{array}$ \\
\hline $\begin{array}{l}\text { Actute renal failure } \\
\text { Auter faliva }\end{array}$ & 6,2(1) & $5,6(2)$ & 0 & $\begin{array}{l}p=0,567 \\
p=0.613\end{array}$ \\
\hline $\begin{array}{l}\text { Hemorrhage Diges } \\
\text { Heart failure /A. fibrillation }\end{array}$ & $\begin{array}{l}0 \\
0\end{array}$ & $\begin{array}{l}2,8(1) \\
2,8(1)\end{array}$ & $0_{0}^{0}$ & $\begin{array}{l}P=0,613 \\
P=0.613\end{array}$ \\
\hline Infection Soft Tissue & & $2,8(1)$ & 0 & $P=0,613$ \\
\hline $\begin{array}{l}\text { Mepattis } \\
\text { Demattitis }\end{array}$ & 0 & $\begin{array}{l}0 \\
0\end{array}$ & $\begin{array}{l}7,7,(14) \\
3,6(7)\end{array}$ & $\begin{array}{l}P<0,01 \\
p<0,001\end{array}$ \\
\hline $\begin{array}{l}\text { Respiratory Failure: } \\
\text { Distress }\end{array}$ & $6,2(1)$ & & 0 & $P=0,41$ \\
\hline Alveolar Hemorrhage & & $2,8(1)$ & 0 & \\
\hline $\begin{array}{l}\text { Lung Aspergilllosis } \\
\text { Bilateral pneumonia }\end{array}$ & 0 & 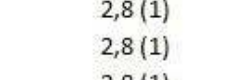 & 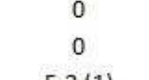 & \\
\hline
\end{tabular}

\section{Results}

We analyzed $70 \mathrm{P}$, with the following distribution according to $C R$ : 1-BUCY $(n=16)$, 2-BEAM / BEAC $(n=35)$ 3-GEMBUMEL $(n=19)$. statistically significant disadvantaging GEMBUMEL ( $\mathrm{p}<0.001)$ related death. When Efficacy was compared, neutrophil recovery was 33,20 and 18 days ( $p$ 0.008), and there were no differences in and the $O S$ at 12 months was $87,94.2$ and94.7\%, with no significant $\mathrm{NHL}$ ) also showed no difference in terms of OS.

\begin{tabular}{|c|c|c|c|c|}
\hline & $\begin{array}{l}\text { Regime 1 } \\
\text { BuCr } \\
(\mathrm{N}=16)\end{array}$ & $\begin{array}{c}\text { Regime 2 } \\
\text { BEAM (23)//BEAC(12) } \\
(\text { (N=35) }\end{array}$ & $\begin{array}{c}\text { Regime } 3 \\
\text { GEBMUMEL } \\
(N=19)\end{array}$ & \\
\hline \multicolumn{4}{|l|}{ Transfusion Requirement } & \\
\hline $\begin{array}{l}\text { Red blood cells } \\
\text { Platelets }\end{array}$ & 17 & 17 & 17.7 & $P=0,901$ \\
\hline $\begin{array}{l}\text { Hematological Recovery } \\
\text { Neutrophils }\end{array}$ & & & & \\
\hline $\begin{array}{l}\text { Neutrophils } \\
\text { Platelets }\end{array}$ & ${ }_{33}$ & 20 & $\begin{array}{llll}18 \\
18\end{array}$ & $p$ \\
\hline \multicolumn{5}{|l|}{$\begin{array}{l}\text { Survival } \\
\text { PFS (\%) to } 12 \text { months }\end{array}$} \\
\hline (\%) to 12 months & 75 & 80 & 78.95 & \\
\hline os (\%) to 12 months & 87.5 & $\begin{array}{l}94.29 \\
\text { 9.257 }\end{array}$ & & $\begin{array}{l}P=0,3163 \\
D=01007\end{array}$ \\
\hline $\begin{array}{l}\text { OS (\%) to } 20 \text { months } \\
\text { PFS } \% \text { ) }\end{array}$ & ${ }_{56525}$ & $\begin{array}{l}88.57 \\
6286\end{array}$ & (78.9. & $\begin{array}{l}P=0,1407 \\
P P=0,581\end{array}$ \\
\hline $\begin{array}{l}\text { os }(\%) \\
\text { os }(\%)\end{array}$ & 62.5 & 68.57 & 94.7 & $\mathrm{P}=0,4108$ \\
\hline $\left.00^{\circ}(1) 1\right)$ & & & 94.7 & $P=0,5114$ \\
\hline
\end{tabular}
dermatitis $(0 \% \mathrm{vs} 0 \% 36.8 \%)$, with no difference in transplantation achieved with a mean of $13,13.8$ and 11 days ( $p$ 0.16) and platelets transfusion requirements. The 12 -month PFS Was 75,80 and $78.95 \%$

\section{Summary}

GEMBUMEL CR presented more toxicity, evidencing a higher incidence of mucositis, hepatitis and dermatitis, while BUCY showed late recovery of $p$ til
between the $C R$.
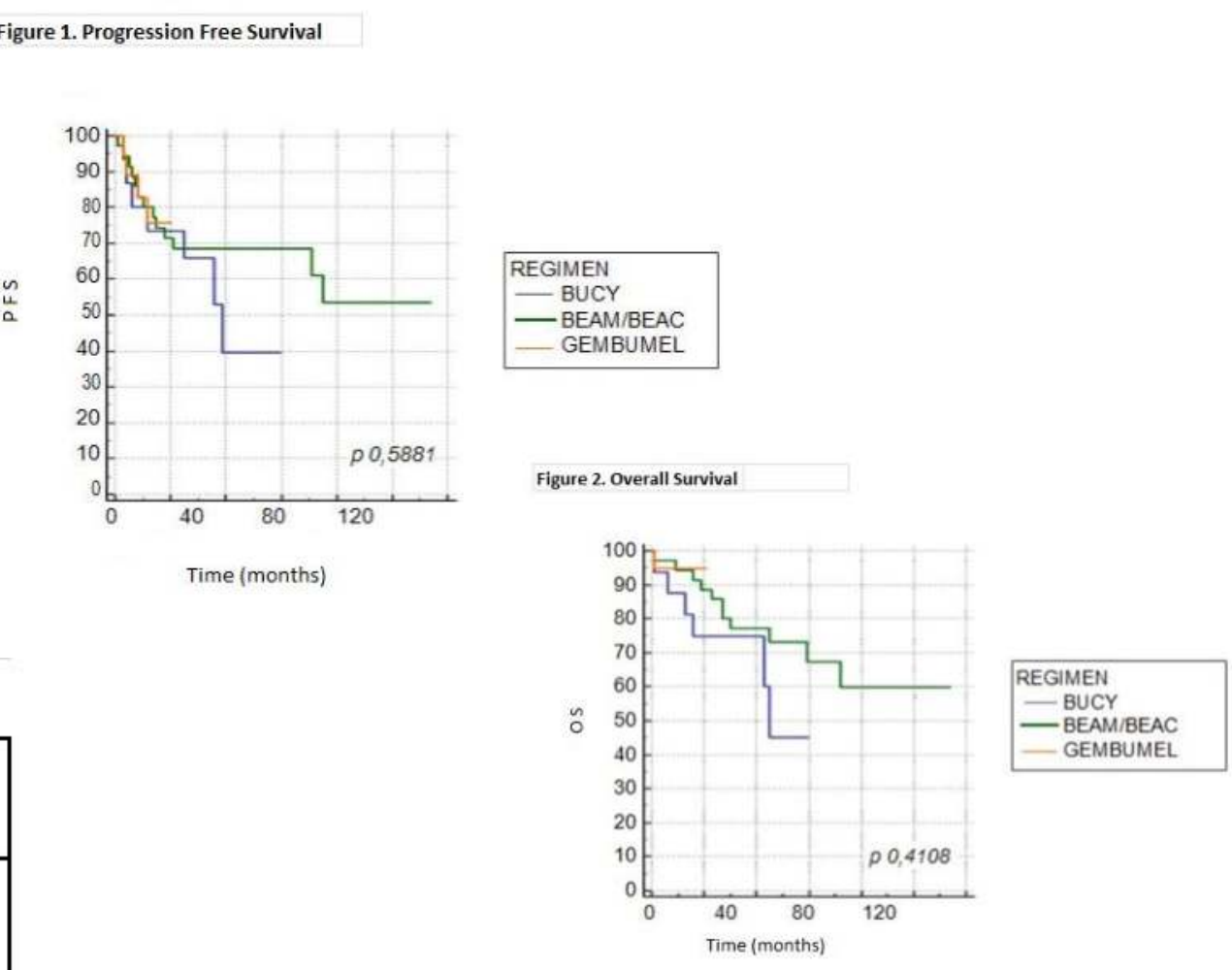

References

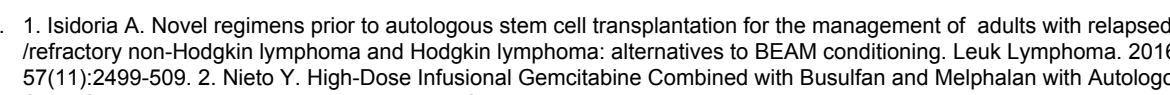

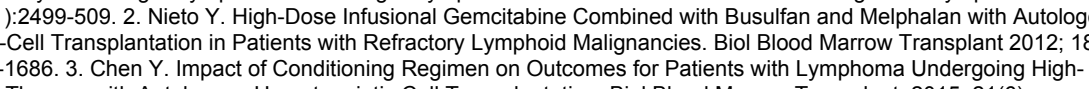

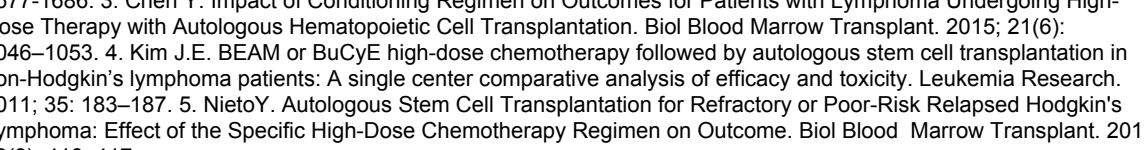

